\title{
Matt Morgan: Fixing our broken wards
}

\author{
Matt Morgan intensive care consultant \\ University Hospital of Wales
}

As I reach the top of the staircase a faded sign reads, "Block A, Tower 3, Wards 7F and 6G." Nobody really knows what these characters mean or how they help to navigate the twists of an ever changing, expanding hospital. A patient looks up and down at a clutched paper letter, wondering if they're going the right way. A hospital porter senses their disorientation and points them back towards the way they've already come.

As I approach the door of the ward, I see a line of relatives huddled around a buzzer with "ONLY PRESS ONCE" taped over its scratched buttons. Once a minute, once an hour, once a day? A busy nurse, looking after patients and supporting families, hears the buzzer's call but can't answer it. As I open the door with my access card, the opportunity is seized and families flow in. Through that one door come meals, $x$ ray machines, dirty linen, nurses, doctors, patients, and dead bodies. On the ward the relatives peer into different wings, looking for "bed 9 in the 4 bedder," without knowing what that means. As an overflowing catheter bag is quickly carried to the sluice, the dinner trolley is manoeuvred to make room. The height of the desk at the nurses' station is an awkward compromise- too low for my knees to fit underneath and too narrow to house a set of paper notes. As I squeeze in, the computer mouse falls to the floor, hanging helplessly by the wire and swinging like a pendulum. I feel the same.

I want to speak to the patient and her family. I think that the patient is going to die. The cloth curtains around the bed are too thin to contain this news from the well wishers next door, so I look for a more private area. ("Just use the office, it should be empty.") I don't want to use the office. This is a hospital ward. It should be the perfect environment to do all of this-for conversations to be spoken, for food to be eaten, for patient care to happen, and for medicine to work.
Yet the many hospital wards I've visited all over the world have a design that's changed little since the late 18th century. It's time to reimagine it. The general ward should have as much consideration as a shiny new operating theatre or boardroom. Wards need separate entrances for utilities and families-even a circular design with dividing walls. Natural light and noise reduction technology would aid sleep, and communal areas would encourage socialising, rather than eating in a chair next to the bed. We need separate areas where intimate examinations, treatments, and even difficult conversations can happen. These should be large enough to house a hospital bed and a supportive family. We should replace faded signs and use floor maps, with directions to toilets and exits, that are shown to nudge human behaviour.

Think too about staff. Central workspaces should encourage thoughtful work with additional areas close to patients, for individualised care. Zoned areas could indicate different levels of need and safe "wander paths," allowing movement even when patients are unwell. And ageing posters that fail to change behaviour could be replaced with art that encourages reflection and has been shown to aid recovery. Hospital needs to be a place that promotes healing, not one that simply delivers it.

\section{Competing interests: I have read and understood BMJ policy on declaration of} interests and declare that I have no competing interests.

Commissioned; not externally peer reviewed.

Matt Morgan is an honorary senior research fellow at Cardiff University, consultant in intensive care medicine and research lead in critical care for Wales, and an editor of BMJ OnExamination. His first book, Critical, was published in 2019.

Published by the BMJ Publishing Group Limited. For permission to use (where not already granted under a licence) please go to http://group.bmj.com/group/rights-licensing/ permissions 